\title{
Attributes of a Magnetic work environment, and its relation to work stress among nursing staff at Children's Cancer Hospital Egypt (CCHE 57357)
}

\author{
Sanaa Abdel-Azeem Ibrahem, Rasha Ibrahim El-Sayed Aly* \\ Nursing Administration, Faculty of Nursing-Port Said University, Egypt
}

Received: August 29, 2017

DOI: $10.5430 /$ cns.v6n1p35
Accepted: October 24, 2017

Online Published: October 26, 2017

URL: https://doi.org/10.5430/cns.v6n1p35

\begin{abstract}
Background: The Magnet hospital is the hospital that implements specific organizational attributes in order to achieve a high quality of care through well-qualified and committed nursing staff.

Aim of the study: The study was aimed at studying attributes of the Magnetic work environment, and its relation to work stress among nursing staff.

Methods: Setting: It was carried out in the children's cancer hospital, Egypt. Design: Using a descriptive correlational design. Subjects: Consisted of 172 nursing staff. Tools and procedure: two different self-administered tools were utilized (Magnet attributes questionnaire, and stress questionnaire). The fieldwork lasted from April to July 2016.

Results: The study revealed that the highest percentage of nursing staff aged between 20 and 30 years. Nearly two thirds (64\%) were having a bachelor degree in nursing. Total attributes of work environment were available with strength. $96.6 \%$ of nursing staff recorded low scores of stress.

Conclusions: The nursing staff in the study setting considered "total attributes of Magnet work environment" as an area of strength. The total scores of stress were generally low. Statistically significant negative correlations were revealed between the scores of total Magnet attributes and stress.

Recommendations: It is a matter of priority for Egyptian children's cancer hospital to enhance and promote the development and maintenance of Magnetism and taking the lead in promoting the status of Magnetism in Egypt.
\end{abstract}

Key Words: Magnetic work environment, Attributes, Work stress, Nursing staff

\section{INTRODUCTION}

In today's highly competitive healthcare environment, and with the high requirements of safe, efficient, effective, and timely patient centered care demonstrated by healthcare providers the Magnet status provide a system for organizing the nursing care processes. Magnet status is not an award; it is a credential of organizational recognition of nursing excellence. ${ }^{[1]}$ According to American Nurses Credentialing Center, ${ }^{[2]}$ Magnet status is a worldwide recognition awarded for hospitals who have the highest quality of nursing care. Additionally, the Magnet connotation is an organizational performance influence the behavior of nurses so that they choose to stay in the health care organization. ${ }^{[3]}$ Moreover,

\footnotetext{
${ }^{*}$ Correspondence: Rasha Ibrahim El-Sayed Aly; Email: rashamoheb@gmail.com; Address: Nursing Administration, Faculty of Nursing-Port Said University, Egypt.
} 
the Magnet concept allows the opportunity for empowerment, progressive leadership and organized transformational processes, autonomy, quality improvement, professional practice, and improved working conditions. ${ }^{[4]}$

According to Jones-Schenk ${ }^{[5]}$ and McClure \& Hinshaw, ${ }^{[1]}$ the Magnet Recognition Program includes fourteen attribute are called "attributes of Magnetism" serve as the fundamental guidelines for establishing a Magnetic structure include: Quality of nursing leadership, Organizational structure, Personnel policies and programs, Professional models of care, Quality assurance, Community and the hospital, Image of nursing, Management style, Quality of care, Level of autonomy, Consultation and resources, Nurses as teachers, Nursephysician relationships, and Professional development.

The nursing work environment is the sum of various elements that directly or indirectly affect the patient care system. Some studies show that Magnet hospitals provide a healthier working environment for nursing staff, accompanied by higher nurse satisfaction and better patient prognosis. ${ }^{[6]}$ Moreover, Magnet hospitals are known to be highly successful in attracting and retaining nurses, as they provide nurses' excellent work environments, resulting in high job satisfaction, low intention to leave, and minimum level of job stress. ${ }^{[7,8]}$

Schwab ${ }^{[9]}$ mentioned that Stress is a global problem in the nursing profession; Stress passive effects include: sickness, poor quality of care, low job satisfaction, staying away from work for long time, and job turnover which considered as financially costly to any health care organization. Furthermore, stress is associated with poor performance, low efficiency, disability to perform, low initiatives, lake of interest in working, high rigidity in thoughts, and lack of concern for colleagues and the organization. ${ }^{[10,11]}$

Individuals experience stress early, even before they come to a life. A certain level or degree of stress may be acceptable to remain alive. ${ }^{[12]}$ According to Laal, ${ }^{[13]}$ stress has a multivariate effects on nurses' behavior including a proper and improper reactions resulting in different health problems, including: anxiety, deterioration in eating habits, sleep pattern disturbance, depression, and substance abuse. Farquharson et al., ${ }^{[14]}$ added that Stress can affect the nurses' general health status, the quality of the services they provide, and their desire to remain in nursing.

According to a "demand-perception-response" perspective. Stress due to individuals' conception of the requirements being made on them and their perception of their ability to meet those requirements. A mismatch means that an individuals' stress attack is exceeded, triggering a stress response. ${ }^{[15]} \mathrm{In}$ ternational Labour Organization ${ }^{[16]}$ stated that work stressors include shift hours, shift work, role overload, responsibility, and the working environment. Furthermore, French et al. ${ }^{[17]}$ indicated that emotionally demanding patient contacts, lack of time to plan and prepare work, frequent interruptions, and responsibility in the absence of decision-making power are important stressors in the nursing profession. According to McVicar ${ }^{[18]}$ and Haybatollahi, ${ }^{[19]}$ professional conflict and the emotional exhaustion, pay, and shift work is the major work stressors in the nursing profession.

Labrague $^{[20]}$ reported that work stress could be due to a new work environment, conflict in clinical practice, nonprofessional nursing skills, uncommon patients' diagnoses and treatments, patients' physical, psychological and social care, fear of occurrence of mistakes, medication administration to children, and the death of patient. Other reasons for stress include negative interaction with supervisors, clinical staff, and physicians.

According to Ojekou \& Dorothy, ${ }^{[21]}$ work environment has a considerable impact on nurses' level of stress. Some attributes in nursing work environments can promote the development of professionals and provide safe practices such as, the quality-focused care, organizational relationships, responsibility and accountability, professional authority, promotion of nursing leadership, support for the professional development of nurses, and the development of cooperative relationships among health workers. ${ }^{[22]}$ In the Magnet hospitals, nursing staff recognize their responsibilities and provided effective leadership based on considerable discretion given by their organization which kept a low stress and turnover of nurses. ${ }^{[23]}$ Magnet hospitals allow the opportunities for having the control over the work environment among nursing staff even at the nursing department level, including opportunities to make the budget plan and experiment with innovative staffing patterns this could influence the level of nurses' job satisfaction and work stress. ${ }^{[24]}$

\subsection{Significance of the study}

Improving the nursing work environment is a focal point and challenge for healthcare organizations and nursing administrators. Therefore, administrators in Magnet hospitals usually apply innovative techniques of the nursing work environment to maintain and improve the health of the environment. ${ }^{[6]}$ Children's Cancer Hospital Egypt (CCHE 57357) have a variety and different categories of nursing staff working in all units and involved in decision-making in patient care delivery, and research-based nursing practice. So that the present study aim is to provide scientific base and an advanced future vision for CCHE to be one of the Magnetic hospitals in the world. 


\subsection{Aim of the study}

The aim of the present research is to study attributes of the Magnetic work environment, and its relation to work stress among nursing staff at Children's Cancer Hospital Egypt (CCHE 57357).

Research objectives:

(1) Measure the attributes of Magnetic work environment at CCHE 57357.

(2) Determining work stress among nursing staff at CCHE 57357.

(3) Finding out the relation between attributes of the Magnetic work environment and work stress among nursing staff at CCHE 57357.

\section{SubJeCts \& Methods}

\subsection{Technical design}

\subsubsection{Research design}

A descriptive co-relational design was used in conducting this study.

\subsubsection{Setting}

The study was carried out in CCHE 57357, located in Cairo, Egypt, is one of the world major hospitals specialized in children's cancer. CCHE 57357 is integrated Services children's cancer hospital provide all the types of care services that children with cancer need. It includes 260 beds and a 60-bed inpatient branch in Tanta, a Governorate in Egypt's Delta region, around $90 \mathrm{~km}$ from Cairo.

The hospital composed of different departments including: outpatient services (a large outpatient capacity, accommodate 400 patients per day. Multi-specialty clinics such as pain, cardiology, dental and ophthalmology), specialized clinical pharmacy offering a variety of services (drug dispensing, intravenous drug admixture, pain management, personalized medication management, drug information services, and drug compounding), clinical nutrition department and nutritional support services, patient education and palliative care services, intensive care units, bone marrow transplant units, a comprehensive surgery department, specialized department of psychology, social work and psychiatry. Moreover, comprehensive physiotherapy department including hydrotherapy, electrotherapy, and latest workout equipment, radiology department, blood donation bank, and clinic. In addition to, child life program and school for hospitalized children, and play areas throughout the hospital departments.

\subsubsection{Sampling design}

The study sample included all nursing staff (staff nurses, head nurses, supervisors, and nursing managers) working in the hospital during the time of the study with a total number of 172. The highest percentage of nursing staff aged between
20 and 30 years and their experience years ranged between 5 and 10 . More than half $(59.3 \%)$ were males. Nearly two thirds $(64 \%)$ were having a bachelor degree in nursing. The majority of the nursing staff were married $(62.2 \%)$.

\subsection{Tools of data collection}

Two different tools were used in the study for data collection.

Tool (1): Magnet attributes tool: it consisted of the following parts:

- Part I: Included questions about nursing staff personal and job characteristics data such as work unit, age, nursing qualification, and years of experience.

- Part II: Part II was utilized to measure the attributes of Magnetic work environment from nursing staff's perception, the tool was adapted from Abd Elkader ${ }^{[25]}$ and composed of 14 attribute as follow: quality of nursing leadership (20 sub items), organizational structure (5 sub items), personnel policies \& procedures ( 9 sub items), nurses as teachers (10 sub items), image of nursing (10 sub items), collegial nurse/physician relationship (10 sub items), management style (11 sub items), quality of care (11 sub items), autonomy (5 sub items), quality improvement (11 sub items), consultation \& resources (5 sub items), community involvement (4 sub items), professional development (15 sub items), and professional models of care (5 sub items). Responses of the participants were measured on the 5-point Likert scale ranging from; 1 = "strongly disagree" to $5=$ "strongly agree". Nursing staff's responses were ranged from area of weakness (low scores $\leq 50 \%$ ); area that needs improvement (moderate scores $=50 \%-75 \%$ ), an area of strength (high scores $\geq 75 \%) .{ }^{[26]}$

Tool (II): Stress questionnaire: This tool was utilized to determine work stress among nursing staff. The tool was developed by the researchers based on review of related literatures. ${ }^{[17,18,27-31]}$ It includes 4 items which consists of 40 sub items, Lack of energy (14 sub items), Somatic symptoms (4 sub items), Depressive/anxious humor (11 sub items), and Depressive thoughts (11 sub items). Overall scores were divided into categories as follows: low level of stress (low scores $\leq 65 \%$ ); Moderate level of stress (moderate scores $=65 \%-75 \%$ ), and finally high level of stress (high scores $\geq 75 \%)$

\subsection{Administrative design and ethical considerations}

An official letter addressed from the Dean of the Port Said Nursing College to CCHE medical and nursing directors to obtain their permission for conducting the study. The hospital Scientific and Medical Advisory Committee (SMAC) 
reviewed the research proposal for scientific and ethical acceptability and safety to participants, the efficiency of scientific methods, the intended level of collaboration, the competency of the research team, and economic benefits whether responsive to clinical and research priorities of CCHE 57357. Moreover, SMAC reviewed the proposed amendments, and structure.

\subsection{Operational design}

Preparatory phase: During this phase, the researchers reviewed the literature related to the study subject using paper and electronic sources both locally and internationally. This helped in the selection and preparation of the data collection tools.

Content validity: Upon preparation of the preliminary forms of the tools, they were presented to a panel of 7 experts for face and content validation. They were from Nursing Administration departments, Faculties of Nursing. Following their opinions, minor modifications were applied. The tools were then modified according to their recommendations and suggestions.

Testing reliability: Cronbach alpha coefficient was calculated to assess the reliability of the tools through their internal consistency. The result for the Magnet attributes questionnaire was Cronbach's alpha $=0.956$ as the reliability of tool was measured in a previous study and it was Cronbach's alpha $=$ 0.977, and for the stress tool was Cronbach's alpha $=0.899$.

Pilot study: $10 \%$ of nursing staff were included in the pilot study. The purposes of the pilot study were to ascertain the clarity and feasibility of the tools and to detect any possible problems concerning data collection tools that might face the researchers and interfere with data collection. It also helped to identify the suitable time and place for data collection and to estimate the exact time needed for data collection.

The field work: After obtaining an official agreement from the hospital SMAC, the hospital directors, the researchers met with the nursing staff, explained to them the aim and process of the study, and invited them to participate. The self-administered questionnaires were distributed to those who gave their consent to participate. Each nursing staff took a time duration about 25-30 minutes to fill in the form. The data were collected from nursing staff along four months from April 1 to August 1. The setting was visited two days per week for four hours each time.

\subsection{Statistical analysis}

Data entry and statistical analysis were done using SPSS (statistical software package of social science) 18.0. Data were presented using Descriptive statistics including frequency, distribution, mean, median, standard deviation and interquartile range were used to describe different characteristics. Kolmogorov-Smirnov test was used to examine the normality of data distribution. Univariate analyses including Kruskal Wallis test and Mann Whitney test were used to test the significance of results of quantitative variables. Chi-Square test and Monte Carlo test were used to test the significance of results of qualitative variables. A Linear correlation was conducted to show the correlation between scores of Magnet attributes scale and stress scale among the studied nurses at Children Cancer Hospital Egypt 57357 using Spearman Rho coefficient. The significance of the results was at the 5\% level of significance.

\section{RESULTS}

Table 1 shows more than three-quarters of nursing staff (81.4\%) agree that "total attributes of work environment" were available with strength. More obviously "professional models of care, and quality of care" attributes record the highest percentage among nurses $(89.5 \%$ and $89 \%$ consecutively); followed by "consultation \& resources and quality improvement" attributes ( $84.3 \%$ and $83.8 \%$ consecutively). On the other hand "autonomy and image of nursing" attributes record the lowest percentage among nursing staff ( $74.4 \%$ and $69.2 \%$ consecutively). Followed by "nurses as teachers and collegial nurse/physician relationship" attributes $(75.0 \%)$. Regarding the other work environment attributes "quality of nursing leadership, organizational structure, management style, personnel policies \& procedures, community involvement, and professional development" above threequarters of nursing staff got positive response.

Table 2 demonstrates that $96.6 \%$ of nursing staff at CCHE 57357 recorded low scores of stress. The percentages of those who have high stress represent only $1.7 \%$.

Table 3 Investigating the relations among nurses' scores of total Magnet attributes and stress, statistically significant negative correlations were revealed between the scores of total Magnet attributes and stress $(r=-0.298)$. Moreover, statistically significant negative correlations were revealed between the scores of all Magnet attributes and Lack of energy, depressive/anxious humor, and depressive thoughts, while somatic symptoms of stress have statistically significant negative correlations with the quality of nursing leadership, management style, and quality of care attribute only.

\section{Discussion}

The Magnet structure provides hospitals with the opportunity to apply attributes and processes support them to achieve their goals, improving the quality of care provided, and increasing employees' achievement. The causes for the great 
concern about Magnet structure is that hospitals in need to treat their structures by allowing nursing staff to contribute to decision-making, and increase their accountability and responsibility that, in turn, can motivate the sense of image and professionalism. ${ }^{[32]}$ According to Hawke, ${ }^{[33]}$ hospitals must work hard, demonstrate a deep commitment to nursing, and often undergo major organizational change to meet the Magnet requirements.

The aim of the present research was to study attributes of the Magnetic work environment and its relation to work stress among nursing staff at CCHE 57357. The study findings re- vealed that more than three-quarters of nurses (81.4\%) agree that "total attributes of work environment" were available and were considered as an area of strength at CCHE 57357. This finding could be attributed to that nursing staff at Hospital 57357 receiving respect, appreciation, empowerment, and recognition for the noble mission they are entrusted to carry out. Additionally, they receive continuous training from day one of working and along their career path that emphasizes the use of teamwork with team spirit and enables them to excel in their job and motivate them to explore new paths for career improvement and professional enhancement.

Table 1. Percent scores of Magnet attributes among the studied nurses at CCHE 57357

\begin{tabular}{|c|c|c|c|c|c|c|}
\hline \multirow{3}{*}{ Domains } & \multicolumn{6}{|c|}{ Magnet attributes score } \\
\hline & \multicolumn{2}{|c|}{$\begin{array}{c}\text { Area of weakness } \\
(\leq \mathbf{5 0 \%})\end{array}$} & \multicolumn{2}{|c|}{$\begin{array}{c}\text { Needs improvement } \\
(50 \%-75 \%)\end{array}$} & \multicolumn{2}{|c|}{$\begin{array}{c}\text { Area of strength } \\
(\geq 75 \%)\end{array}$} \\
\hline & No. & $\%$ & No. & $\%$ & No. & $\%$ \\
\hline Quality of Nursing Leadership & 2 & 1.2 & 35 & 20.3 & 135 & 78.5 \\
\hline Organizational Structure & 2 & 1.2 & 33 & 19.2 & 137 & 79.6 \\
\hline Management Style & 2 & 1.2 & 31 & 18.0 & 139 & 80.8 \\
\hline Personnel Policies \& Procedures & 0 & 0.0 & 28 & 16.3 & 144 & 83.7 \\
\hline Professional Models of Care & 0 & 0.0 & 19 & 11.0 & 153 & 89.0 \\
\hline Quality of Care & 0 & 0.0 & 18 & 10.5 & 154 & 89.5 \\
\hline Quality Improvement & 3 & 1.7 & 25 & 14.5 & 144 & 83.8 \\
\hline Consultation \& Resources & 4 & 2.3 & 23 & 13.4 & 145 & 84.3 \\
\hline Autonomy & 17 & 9.9 & 36 & 20.9 & 119 & 69.2 \\
\hline Community Involvement & 4 & 2.3 & 26 & 15.1 & 142 & 82.6 \\
\hline Nurses as Teachers & 9 & 5.2 & 34 & 19.8 & 129 & 75.0 \\
\hline Image of Nursing & 13 & 7.6 & 31 & 18.0 & 128 & 74.4 \\
\hline Collegial Nurse/Physician Relationship & 9 & 5.2 & 34 & 19.8 & 129 & 75.0 \\
\hline Professional Development & 0 & 0.0 & 28 & 16.3 & 144 & 83.7 \\
\hline Total score & 0 & 0.0 & 32 & 18.6 & 140 & 81.4 \\
\hline
\end{tabular}

Table 2. Percent scores of stress scale among the studied nurses at CCHE 57357

\begin{tabular}{|c|c|c|c|c|c|c|}
\hline \multirow{3}{*}{ Stress Scale } & \multicolumn{6}{|c|}{ Stress score } \\
\hline & \multicolumn{2}{|c|}{ Low $(\leq 65 \%)$} & \multicolumn{2}{|c|}{ Moderate (65\%-75\%) } & \multicolumn{2}{|c|}{ High $(\geq 75 \%)$} \\
\hline & No. & $\%$ & No. & $\%$ & No. & $\%$ \\
\hline Lack of energy & 158 & 91.8 & 7 & 4.1 & 7 & 4.1 \\
\hline Somatic symptoms & 153 & 89.0 & 0 & 0.0 & 9 & 11.0 \\
\hline Depressive/anxious humor & 160 & 93.0 & 8 & 4.7 & 4 & 2.3 \\
\hline Depressive thoughts & 163 & 94.7 & 7 & 4.1 & 2 & 1.2 \\
\hline Total score & 166 & 96.6 & 3 & 1.7 & 3 & 1.7 \\
\hline
\end{tabular}

In congruence with this, Abdullah ${ }^{[34]}$ stated that Magnet hospitals allow opportunities for nursing staff to participate in the hospital' activities, focus on the nurse managers' abilities, and the coefficient relationship between the physicians and nurses. Moreover, Kramer and Schmalenberg ${ }^{[35]}$ studied the factors which the nursing staff considered it as important for being able to provide high quality care, stated that these factors includes, sharing the work with competent nurse, pro- fessional nurse-physician relationship, effective communication, autonomy and accountability of nurses, empowerment of nurse manager/supervisor, control over nursing practice and work environment, educational opportunities, effective staffing, and concern for the patient.

Concerning the 14 attributes of Magnetic work environment the current study findings indicated that "professional models of care, and quality of care" attributes record the highest 
percentage among nursing staff and were considered as the highest areas of strength at CCHE $(89.5 \%$ and $89 \%$ consec- utively); followed by “consultation $\&$ resources and quality improvement" attributes ( $84.3 \%$ and $83.8 \%$ consecutively).

Table 3. Correlation between scores of Magnet attributes scale and stress scale among the studied nurses at CCHE 57357

\begin{tabular}{|c|c|c|c|c|c|c|c|c|c|c|}
\hline \multirow{3}{*}{$\begin{array}{l}\text { Score }(\%) \text { of Magnet attributes } \\
\text { domains }\end{array}$} & \multicolumn{10}{|c|}{ Scores (\%) of Stress Scale } \\
\hline & \multicolumn{2}{|c|}{ Lack of energy } & \multicolumn{2}{|c|}{ Somatic symptoms } & \multicolumn{2}{|c|}{$\begin{array}{c}\text { Depressive/anxious } \\
\text { humor }\end{array}$} & \multicolumn{2}{|c|}{ Depressive thoughts } & \multicolumn{2}{|c|}{ Total score } \\
\hline & $\mathbf{r}$ & $p$ & $\mathbf{r}$ & $p$ & $\mathbf{r}$ & $p$ & $\mathbf{r}$ & $p$ & $\mathbf{r}$ & $p$ \\
\hline Quality of Nursing Leadership & -0.383 & $.0001^{*}$ & -0.035 & .646 & -0.282 & $.0001^{*}$ & -0.337 & $.0001^{2}$ & -0.360 & $.0001^{*}$ \\
\hline Organizational Structure & -0.301 & $.0001^{*}$ & -0.153 & $.046^{*}$ & -0.261 & $.001^{*}$ & -0.269 & $.0001^{*}$ & -0.337 & $.0001^{*}$ \\
\hline Management Style & -0.275 & $.0001^{*}$ & -0.173 & $.024^{*}$ & -0.180 & $.018^{*}$ & -0.282 & $.0001^{*}$ & -0.302 & $.0001^{*}$ \\
\hline Personnel Policies \& Procedures & -0.209 & $.006^{*}$ & -0.107 & .163 & -0.146 & .057 & -0.257 & $.001^{*}$ & -0.241 & $.001^{*}$ \\
\hline Professional Models of Care & -0.237 & $.002^{*}$ & -0.041 & .590 & -0.093 & .225 & -0.164 & $.032^{*}$ & -0.189 & $.013^{*}$ \\
\hline Quality of Care & -0.203 & $.008^{*}$ & -0.152 & $.047^{*}$ & -0.233 & $.002^{*}$ & -0.182 & $.017^{*}$ & -0.248 & $.001^{*}$ \\
\hline Quality Improvement & -0.184 & $.016^{*}$ & -0.075 & .325 & -0.196 & $.010^{*}$ & -0.188 & $.014^{*}$ & -0.215 & $.005^{*}$ \\
\hline Consultation \& Resources & -0.212 & $.005^{*}$ & -0.111 & .149 & -0.241 & $.001^{*}$ & -0.186 & $.014^{*}$ & -0.235 & $.002^{*}$ \\
\hline Autonomy & -0.164 & $.031^{*}$ & 0.037 & .630 & -0.173 & $.023^{*}$ & -0.196 & $.010^{*}$ & -0.170 & $.026^{*}$ \\
\hline Community Involvement & -0.176 & $.021^{*}$ & 0.004 & .955 & -0.177 & $.021^{*}$ & -0.157 & $.039^{*}$ & -0.176 & $.021^{*}$ \\
\hline Nurses as Teachers & -0.151 & $.048^{*}$ & -0.078 & .308 & -0.172 & $.024^{*}$ & -0.174 & $.023^{*}$ & -0.178 & $.020^{*}$ \\
\hline Image of Nursing & -0.223 & $.003^{*}$ & 0.047 & .541 & -0.177 & $.020^{*}$ & -0.161 & $.035^{*}$ & -0.192 & $.012^{*}$ \\
\hline Collegial Nurse/Physician Relationship & -0.241 & $.001^{*}$ & -0.068 & .377 & -0.255 & $.001^{*}$ & -0.199 & $.009^{*}$ & -0.246 & $.001^{*}$ \\
\hline Professional Development & -0.273 & $.0001^{*}$ & -0.105 & .170 & -0.275 & $.0001^{*}$ & -0.238 & $.002^{*}$ & -0.289 & $.0001^{*}$ \\
\hline Total score & -0.293 & $.0001^{*}$ & -0.066 & .391 & -0.253 & $.001^{*}$ & -0.272 & $.0001^{*}$ & -0.298 & $.0001^{*}$ \\
\hline
\end{tabular}

Note. r: Spearman Rho correlation coefficient; " significant at $p \leq .05$

This might reflect the high-quality services provided by nursing staff in CCHE, through following the health professions act, establishing, monitoring, and enforcing standards of practice and professional ethics and commitment to quality, applying evidence-based practices, advanced leadership, and promoting a healthy work environment. Which results in earning awards and accreditation: In 2009, the hospital Chief Nursing Officer has been awarded best nursing leadership prize on the national level from the Egyptian Nursing Syndicate. Children's Cancer Hospital, Egypt is accredited as a provider of continuing nursing education by the American Nurses Credentialing Centre's Commission on Accreditation. The foregoing present study findings are in agreement with Rodwell and Demir ${ }^{[36]}$ who claimed that Magnet hospitals are associated with "concepts of good quality care, continuing education, professional autonomy, flat structures, effective staff deployment, and high levels of job satisfaction".

On the other hand, as revealed by the findings of the current study, "autonomy and image of nursing" attributes record the lowest percentage among nursing staff $(69.2 \%$ and $74.4 \%$ consecutively). Followed by "nurses as teachers and collegial nurse/physician relationship" attributes $(75.0 \%)$. This is a worrying finding given the importance of autonomy and image of nursing and its essentiality in Magnet work environment. This finding could be due to the scope of practice and activities that nurses were educated and authorized to perform were established through the legislated definition of nursing practice and were complemented by standards, limits, and conditions set by CCHE. Kramer, Schmalenberg \&
Maguire $^{[37]}$ agreed up on aforementioned explanation clarifying that autonomy is the freedom to act on what one knows, to make independent clinical decisions that exceed standard nursing practice, in the best interest of the patient.

Hart et al. ${ }^{[38]}$ and Davey ${ }^{[3]}$ suggested essential characteristics for being Magnet hospital which include: A formal membership of the hospital governing boards for nursing director, supportive organizational structures and administration for nurses' decisions regarding patient care, open door policy by nurse leaders and managers, professional autonomy over practice, good collaboration between nurses, physicians, and administrators, and work structure ensuring nurse participation in policy decisions.

Furthermore, Regarding the other work environment attributes "quality of nursing leadership, organizational structure, management style, personnel policies \& procedures, community involvement, and professional development" above three-quarters of nurses got a positive response. It could be due to, that nursing leaders in the hospital act as a driving force of the hospital, strongly influencing the professional practice, which in turn influenced the degree of work engagement among nurses. As well as, nursing staff is an integral part of the health care team, taking part in combined clinics and sharing their valuable feedback for a better assessment of patient conditions. Moreover, the hospital supports the professional growth and academic advancement through In-service training, continuing education, and leadership \& management programs.

In agreement with this, Lake ${ }^{[39]}$ identified 5 factors as charac- 
teristics of effective nursing practice environments including effective nursing leadership, staff participation in organizational affairs, adequate staffing for quality care, support for a nursing model of patient care, and effective nurse/physician relationships. According to Buffington et al. ${ }^{[40]}$ Extroverted leader personalities with transformational and transactional leadership styles are the most successful in retention and in engaging the individual nurse in professional development both intellectually and clinically.

Another main objective of the present study was to determine work stress among nursing staff at CCHE 57357. The findings were illustrated that $96.6 \%$ of nursing staff recorded low scores of stress. The percentages of those who have high stress represent only $1.7 \%$. This could be explained by the shared values of a children's cancer hospital that include: the staff commitment, integrity, trustful and respectful relationships, accountability for all stakeholders (patients, families, colleagues, donors, public, government and educational agencies), professional communication and interaction according the standards and codes of performance, teamwork and partnership through collaboration which fosters efficiency and effectiveness, personal and professional development through continuous expand of knowledge, evidence based principles, creativity and appreciation of creativity in others, the change through valuing change as a positive for continuous improvement of the hospital and the individual, diversity of cultures, social responsibility toward the community to provide a center of excellence.

In agreement with the previous exploration, ${ }^{[41]}$ McClure et al. stated that stress decline when nursing staff has a sense of competency and empowerment. Moreover, stress was decreased when nurses believe that their role is essential to the organizational mission and that they have legitimate accountability for the quality of patients care. Ressler ${ }^{[42]}$ reported that the individuals experience stress whenever they are faced with an event or situation they perceive as challenging to their ability to cope. Wu et al. ${ }^{[43]}$ and Urbanetto et al. ${ }^{[44]}$ added that training programs and staff's coping strategies in unfavorable work situations representing an important protective factor for the health of nursing professionals within the work climate. Moreover, The American Nurses Association reported that nurses' stress occurs as a result of Physical violence by patients, patients' family members, or strangers against nurses or by "lateral", violence in the form of incivility, disruptive behavior, verbal aggression, and bullying tend to be perpetrated by other nurses, nurse managers, physicians, and other co-workers. ${ }^{[11]}$

In disagreement with the previous study findings, Haybatollahi ${ }^{[19]}$ conducted a study about stress on military nurses and indicated that nurses reported high level of job stress as a result of lack of support from supervisors, high responsibility, long working hours, and role overload. Moreover, Swedish' study of stress among a large sample of nurses revealed that most study nurses reported high to very high level job stress. Furthermore, a study of stress in United Kingdom health authority reported that Nurses were under the greatest pressure among all health care personnel. ${ }^{[10]}$

In examining the relations among nurses' scores of total Magnet attributes and stress, the current study findings revealed significant negative correlations $(r=-0.298)$. Moreover, statistically significant negative correlations were revealed between the scores of all Magnet attributes and Lack of energy, Depressive/anxious humor, and Depressive thoughts, while Somatic symptoms of stress have statistically significant negative correlations with the quality of nursing leadership, management style, and quality of care attribute only. The findings mean that the provision of strength and positive Magnet attributes is associated with lower level of stress.

A forementioned study finding could be again due to the ethics that the hospital has adopted as, the resolution of conflicts through using standards and conflict resolution techniques that are set in the hospital policies, implement fair practices with employees; providing a safe work environment, avoiding discrimination related to gender, creed, or age; and meeting the current local standards for compensation and benefits, and empower personnel to adhere to legal, regulatory and institutional requirements.

In congruence with these findings, Spence Laschinger \& Leiter ${ }^{[45]}$ referred to that professional nursing work environments represent an important role in the quality of nurses' work life. Nurses in these settings have lower levels of stress, burnout, greater job satisfaction, and lower turnover intentions. In the Magnet hospitals, it is a combination of elements that create a positive work climate. It is the effectiveness and efficiency of administration and leadership that differentiate Magnet hospitals from others. Coefficient managers are evidently skillful in providing the proper equilibrium between the needs and interests of clients, staff, and the organizationa. Sarafis et al., ${ }^{[46]}$ added that conflicts with supervisors, doctors, co-workers, professional knowledge and skills, and fear of the treatment effect caused significant level of stress among nurses.

The research studies of Haskins et al. ${ }^{[47]}$ and Rodwell et al. ${ }^{[36]}$ on Magnet hospitals revealed that Magnetic status have a positive correlations with many fundamental factors for nursing. These include personal values, social and physical empowerment, collaboration with other health care professionals, nursing competences, nursing expertise which in turn 
increase job satisfaction and decrease job stress and burnout. Organizations that have Magnet design face challenges include "involving, educating, and keeping their nurses engaged during this long process". However, while there are challenges of the process, there are many advantages within the organization. ${ }^{[48]}$ Factors such as personnel policies and program are the primary forces in the development of a Magnet hospital. Considering the demand for flexible scheduling of nurses, providing a supportive work environment, better leadership, more input in decision making, and greater access to information and resources, and keeping pace with today's changing health care environment could achieve better outcomes for nurses, patients, and hospitals. ${ }^{[49]}$

The Magnet organizations acquired competitive advantage for high quality patient care and professional patient environments because they empower nursing staff to use their professional knowledge and skills on behalf of patients. This is believed to be the key for high quality, safe, and costeffective patient care. Moreover, nurses are primary source of information about changes in patients' conditions among the healthcare team, often have to act in the absence of specialists when timely intervention is required. It has been suggested that the organizational support in Magnet hospitals allow nurses to exercise their professional knowledge, judgment, and skills to initiate interventions that promote patient safety and rescue them and the organization from dire and costly consequences. ${ }^{[50]}$

\section{Conclusions}

Based on study findings, it can be concluded that: more than three-quarters of nursing staff considered that "total attributes of Magnet work environment" as an area of strength at CCHE 57357. More obviously "professional models of care, and quality of care" attributes record the highest percentage among nursing staff. On the other hand "autonomy and image of nursing" attributes record the lowest percentage. The total scores of stress among nursing staff were generally low. Yet, only minorities of nursing staff having high stress. Statistically significant negative correlations were revealed between the scores of total Magnet attributes and stress.

\section{Recommendations}

Based on the findings of the present study, the following recommendations were suggested for health care organizations and CCHE 57357:

- Provide the environment in which nursing staff be able to establish standards, set goals, monitor practice, and measure outcomes function in an autonomous manner.

- Allowing nursing Staff to view themselves as responsible practitioners, capable of making decisions about the nursing care needs of patients.

- Continuing nursing education and staff development activities are urgently needed to improve nursing staff' knowledge and skills. This is of particular importance for nursing autonomy and image of nursing.

- It is a matter of priority for the hospital to enhance and promote the development and maintenance of Magnetism and taking the lead in promoting the status of Magnetism especially in Egypt.

- It is now up to the nursing staff to enhance Magnet hospital designation as a valid indicator of good nursing care and utilize the opportunity for themselves and for their patients.

- The nursing schools' curricula should give more emphasis to Magnet hospitals and status of Magnetism, with more focus on its importance, principles, essentials, and programs.

\section{Conflicts of Interest Disclosure}

The authors declare they have no conflicts of interest.

\section{REFERENCES}

[1] McClure M, Hinshaw A. Magnet Hospitals Revisited: Attraction and Retention of Professional Nurses. Kansas City, Mo.: American Nurses Publishing; 2002.

[2] American Nurses Credentialing Center. Find a magnet hospital. 2014 Available from: www.nursecredentialing.org/Magnet/Find aMagnetFacility

[3] Davey KS. A Review of the Magnet Hospital Concept From the Perspective of Organizational Behavior. Health Care Management. 2010; 7(1): 30-34.

[4] Heitmann A, Čišić RS, Meyenburg-Altwarg I. From Magnet-Hospital to the Hospital of the Future. Nursing and Health. 2013; 1(4): 78-87. https://doi.org/10.1097/00006247-200101000-00017
[5] Jones-Schenk J. How magnets attract nurses. Nursing Management. 2001; 41-42. https://doi.org/10.1097/00006247-2001010 00-00017

[6] Gu LY, Zhang LJ. Assessment tools of nursing work environment in magnet hospitals: A review. International Journal of Nursing Sciences. 2014; 1(4): 437-440. https ://doi.org/10.1016/j.ijns s.2014.10.013

[7] Kelly LA, McHugh MD, Aiken LH. Nurse outcomes in magnet and non-magnet hospitals. The Journal of Nursing Administration. 2011; 41: 428-433. https ://doi.org/10.1097/NNA.0b013e31822e ddbc

[8] Biegger A, De Geest S, Schubert M, et al. The "magnetic forces" of Swiss acute care hospitals: A secondary data analysis on nurses' 
job satisfaction and their intention to leave their current job. Nursing Plus Open. 2016; 2: 15-20.

[9] Schwab L. Individual hardiness and staff satisfaction. Nursing Economics. 1996; 14(3): 171-173. PMid: 8788800.

[10] Rita AA, Atindanbila S, Portia MNP, et al. The Causes of Stress and Job Satisfaction among Nurses at Ridge and Pantang Hospitals in Ghana. International Journal of Asian Social Science. 2013; 3(3): 762-771.

[11] Bouma W, Horst ICCVD, Hamer IJW, et al. Chronic ischaemic mitral regurgitation. Current treatment results and new mechanism-based surgical approaches. European Journal of Cardio-Thoracic Surgery. 2010; 37(1): 170-185.

[12] Middlebrooks JS, Audage NC. The effects of childhood stress on health across the lifespan, U.S. department of health and human services centers for disease control and prevention publishing. 2008. Available from: http://www.cdc.gov/ncipc/pub-res/pdf/C hildhood_Stress.pdf

[13] Laal M. Job Stress Management in Nurses. Procedia - Social and Behavioral Sciences. 2013; 84: 437-442. https : //doi.org/10.1 016/j.sbspro.2013.06.581

[14] Farquharson B, Bell C, Johnston D, et al. Nursing stress and patient care: Real-time investigation of the effect of nursing tasks and demands on psychological stress, physiological stress, and job performance: Study protocol. Journal of Advanced Nursing. 2013; 69(10): 2327-2335. PMid: 23387943. https://doi.org/10.1111/jan. 12090

[15] Clancy J, McVicar A. Physiological and Anatomy: A Homeostatic Approach, $2^{\text {nd }}$ Edition. Chapter 22. London: Annales Universitatis Saraviensis Medizin; 2002. 611-633 p.

[16] International Labour Organization (ILO). Encyclopaedia of Occupational Health and Safety ( $4^{t h}$ ed.). Geneva, Switzerland: International Labour Office; 1998.

[17] French SE, Lenton R, Walters V, et al. An empirical evaluation of an expanded nursing stress scale. J Nurs Meas. 2000; 8.

[18] McVicar A. Workplace stress in nursing: a literature review. J Adv Nurs. 2003; 44. PMid: 14651686. https ://doi.org/10.1046/j . 0309-2402.2003.02853.x

[19] Haybatollahi SM. Work Stress in the Nursing Profession An Evaluation of Organizational Causal Attribution. ( managing editor K. L. A.-M. P.-B. K. M. V. M. W. J. L. Klaus Helkama, chairperson Inga Jasinskaja-Lahti, Ed.) (Social psy). Helsinki, Yliopistopaino: Department of Social Psychology, University of Helsinki; 2009.

[20] Labrague LJ. Stress, stressors, and stress responses of student nurses in a government nursing school. Health Science Journal. 2013; 7(4): 424-435.

[21] Ojekou GP, Dorothy OT. Effect of Work Environment on Level of Work Stress and Burnout among Nurses in a Teaching Hospital in Nigeria. Open Journal of Nursing. 2015; 5: 948-955. https: //doi.org/10.4236/ojn.2015.510100

[22] American Association of Colleges of Nursing. Hallmarks of the professional nursing practice environment. J Prof Nurs. 2002; 18(5): 295-304. https://doi.org/10.1053/jpnu.2002.129231

[23] Tominaga M, Sato F, Michiwaki M. Cross-cultural study concerning leadership and management style of nursing managers: a case study of magnet hospitals in the U.S. and a Japanese hospital. Psyche and Culture. 2012; 11: 169-184.c

[24] McClure M, Pulin M, Sovie M, et al. Mangnet hospitals: attraction and retention of professional nurses, in Magnet hospitals revisited. American Nurses Association. 2002.

[25] Abd Elkader EM. Assessment of magnet professional forces as perceived by administrators and nursing staff at Mansura international specialized hospital, un published master thesis. Egypt: Faculty of Nursing, University Of Alexandria; 2009.

[26] Kramer M, Schmalenberg C. Development and evaluation of essentials of mag- netism tool. Journal of Nursing Administration. 2004; 34(7/8): 1-14.

[27] Gray-Toft P, Anderson JG. The nursing stress scale: development of an instrument. J Behav Assess. 1981; 3. https://doi .org/10.1 $007 / \mathrm{BF} 01321348$

[28] Edwards D, Burnard P. A systematic review of stress and stress management interventions for mental health nurses. J Adv Nurs. 2003; 42. https://doi.org/10.1046/j.1365-2648.2003.02600.x

[29] Folkman S. Stress Questionnaire. Wellness and Self-Care Library. $2011 ; 12$.

[30] Edward KL, Ousey K, Warelow P, et al. Nursing and aggression in the workplace: a systematic review. Br J Nurs. 2014; 23. https : //doi.org/10.12968/bjon.2014.23.12.653

[31] Usdaw Nationwide Central. Stress Questionnaire or pressure on a person. 2014

[32] Sayer J. The attraction of Magnet for NHS trusts. Mental Health Practice. 2011; 14(9): 8-8. https://doi .org/10.7748/mhp201 1.06.14.9.8.p5314

[33] Hawke M. Magnet Status Attracts Mettle. 2004; 19-21.

[34] Abdullah A. Nursing satisfaction in a magnet hospital. 2015. Available from: http://digitalcommons.uri.edu/oa_diss/403/

[35] Kramer M, Maguire P, Brewer BB. Clinical nurses in Magnet hospitals confirm productive, healthy unit work environments. Journal of Nursing Management. 2011; 19(1): 5-17. PMid: 21223400. https://doi.org/10.1111/j.1365-2834.2010.01211.x

[36] Rodwell J, Demir D. The blurring of attractive work practices across health care sectors. Public Personnel Management. 2013; 33(5): 588598. https://doi.org/10.1177/0091026013496076

[37] Kramer BM, Schmalenberg C, Maguire P. Magnetic work environment. Culture. 2008.

[38] Hart K, Lavandero R, Leggett J, et al. Critical care nurses' work environments value of excellence in Beacon units and Magnet organizations. Critical Care Nurse. 2007; 22(3): 68-74.

[39] Lake T. Development of the Practice Environment Scale of the Nurs ing Work Index. Research in Nursing \& Health. 2002; 25(3): 176-188. PMid: 12015780. https://doi.org/10.1002/nur.10032

[40] Buffington A, Zwink J, Fink R, et al. Factors Affecting Nurse Re-

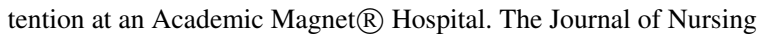
Administration. 2012; 42(5): 273-281. PMid: 22525291. https : //doi.org/10.1097/NNA.0b013e3182433812

[41] McClure ML, Poulin MA, Sovie MD, et al. Magnet hospitals: at traction and retention of professional nurses (original study). Magnet Hospitals Revisited: Attraction and Retention of Professional Nurses. 2002; 1981: 1-24.

[42] Ressler PK. Stress management for nurses. Beginnings (American Holistic Nurses’ Association). 2007.

[43] Wu H, Chi TS, Chen L, et al. Occupational stress among hospital nurses: cross-sectional survey. J Adv Nurs. 2010; 66. https: //doi.org/10.1111/j.1365-2648.2009.05203.x

[44] Urbanetto JDS, Maciel VO, Santanna VM, et al. Work-related stress according to the demand-control model and minor psychic disorders in nursing workers. Revista Da Escola De Enfermagem Da Usp 2013; 47(5): 1180-1186. PMid: 24346460. https ://doi .org/10 .1590/S0080-623420130000500024

[45] Laschinger HKS, Leiter MP. The impact of nursing work en vironments on patient safety outcomes: the mediating role of burnout/engagement. The Journal of Nursing Administration. 2006; 36(5): 259-267. https ://doi .org/10.1097/00005110-20060 5000-00019 
[46] Sarafis P, Rousaki E, Tsounis A, et al. The impact of occupational stress on nurses' caring behaviors and their health related quality of life. BMC Nursing. 2016; 15(1): 56. PMid: 27708546. https://doi.org/10.1186/s12912-016-0178-y

[47] Haskins M, Hnatiuk C, Yoder L. Medical-surgical nurses' perceived value of certification study. MedSurg Nursing. 2011; 22(3): 71-79.

[48] Russell J. Journey to Magnet: cost vs. benefits. Nursing Economics. 2010; 28(5): 340-341. PMid: 21158256.
[49] Yang HY, Yu CH, Wang MJ. Strategic management in the establishment of a magnet hospital: A nursing staff perspective. Health 2013; 5(8): 1318-1327. https://doi.org/10.4236/health.2 013.58179

[50] Lundstrom T, Pugliese G, Bartley J, et al. Organizational and environmental factors that affect worker health and safety and patient outcomes. American Journal of Infection Control. 2002; 30(2): 93 106. PMid: 11944001. https ://doi.org/10.1067/mic.2002.1 19820 